\title{
A VULNERABILIDADE AGRAVADA DA CRIANÇA E DO ADOLESCENTE NO ÂMBITO DA PUBLICIDADE ABUSIVA
}

\author{
Dennis Verbicaro \\ Centro Universitário do Pará (CESUPA), Pará \\ dennis@gavl.com.br \\ Arnaldo Gomes \\ Centro Universitário do Pará (CESUPA), Pará \\ arnaldo.gomes@tjpa.jus.br
}

\begin{abstract}
Resumo: O objetivo do artigo é discutir os efeitos que a publicidade abusiva ocasiona à criança e ao adolescente e como se dá a proteção destes na relação de consumo, por meio do método dedutivo e de pesquisa teórico-bibliográfica. Para tanto, as crianças e os adolescentes serão enquadrados como consumidores hipervulneráveis, pois são portadores de uma vulnerabilidade agravada, justamente por não possuírem uma capacidade de discernimento plenamente desenvolvida. Quando expostos ao assédio de consumo, por meio de técnicas publicitárias abusivas, sofrem sérios prejuízos de ordem psicológica e econômica, bem como danos ao seu desenvolvimento saudável e comportamento social. Conclui-se que o maior empoderamento do consumidor no mercado lhe permite não apenas selecionar melhores fornecedores, que respeitem o adequado desenvolvimento da criança e do adolescente pela veiculação de publicidade responsável, como também pode influenciar a mudança de comportamentos éticos do empresário, seja pela postagem de experiências negativas nas redes sociais e em sites de compartilhamento de experiências, seja pelo boicote de produtos e serviços nocivos ao público infantil.
\end{abstract}

Palavras-Chaves: Publicidade Abusiva. Direito do Consumidor. Hipervulnerabilidade. Criança. Adolescente.

The aggravated vulnerability of children and adolescents in the context of abusive advertising

Abstract: The purpose of this article is to discuss the effects of abusive advertising on children and adolescents and how to protect them in the relation of consumption through the deductive method and theoretical-bibliographic research. In order to do so, they will be classified as hypervulnerable consumers, because they suffer from an aggravated vulnerability, precisely because they do not possess their fully developed capacity for discernment, when exposed to consumer harassment through abusive advertising techniques, causing serious psychological and economic damages, as well as as causing damage to their healthy development and social behavior. It is concluded that the greater consumer empowerment in the market allows him to select better suppliers, who not only respect the adequate development of the child and the adolescent by the publicity of responsible publicity, but also can influence the ethical behavior change of the entrepreneur, either by the post negative experiences on social networks and sites sharing experiences, or for the boycott of products and services harmful to children.

Keywords: Advertising Abusive. Consumer Law. Hypervulnerability. Child. Adolescent. 


\section{INTRODUÇÃo}

O presente artigo discute como a atuação publicitária interfere na formação de opinião das crianças e dos adolescentes enquanto possíveis consumidores e visa demonstrar como a atuação da publicidade abusiva pode manipulá-los para que influenciem seus pais para a aquisição de produtos e serviços. De modo secundário, analisa como a publicidade abusiva pode incorrer na formação de um perfil consumista dos menores, transformando pseudonecessidades (necessidades artificiais criadas pela indústria cultural) em necessidades primárias, no sentido de debater a importância da efetivação de direitos e garantias desses sujeitos considerados hipervulneráveis, para resguardá-los da publicidade abusiva.

No início da Idade Média, a história social da criança e do adolescente não era contada, entretanto, a partir do século XIX, começaram a ser vistos como sujeitos importantes, por isso o autor francês Philippe Ariés passou a dar grande visibilidade a essa categoria. Em seu livro, foi narrado que as crianças e os adolescentes eram tratados como adultos neste período histórico e, como tais, não necessitavam de nenhuma atenção diferenciada.

De acordo com Del Priore (2018), no Brasil, a criança e o adolescente também eram chamados de adultos em miniatura. Como exemplo desta realidade, aos 15 (quinze) anos, já podiam até mesmo se casar. Outro contexto que Del Priore (2018) evidência são as obras de artes nesta realidade, que destacavam a figura da criança mimetizada como adulta.

Ainda afirma Del Priore (2018) que, no ano de 1927, o registro dos filhos servia basicamente para subsidiar o código de menores, cujo objetivo maior era punir adolescentes. Isso porque, naquela época, não havia uma preocupação de mudar a situação do menor, o que só veio a acontecer em 1988, com a promulgação da nossa Carta Magna, onde mudanças significativas, de fato, ocorreram.

No Brasil, antes da Constituição Federal de 1988 e do Código de Defesa do Consumidor (1990), o sistema jurídico já possuía normas que protegiam alguns direitos do consumidor. $\mathrm{Na}$ Carta Magna, foram ajustados os dispositivos dos direitos fundamentais ao tratar de família, adotando o cuidado especial à criança e ao adolescente, pois são categorias que necessitam de proteção em razão da sua vulnerabilidade, devendo ser protegidas de qualquer forma quando expostas a uma condição de exploração.

Os direitos da criança e do adolescente encontram-se resguardados por tratados internacionais, pela Constituição da República do Brasil (1988) e pelo Estatuto da Criança e Adolescente (1990), que garantem a proteção integral e condições dignas para que possam ter crescimento e desenvolvimento saudáveis.

A criança e o adolescente são alvos da publicidade abusiva, pois os anúncios publicitários são instrumentos utilizados para influenciar a aquisição de produtos ou serviços. Os filhos influenciam seus pais ao consumo, tornando-se um potencial comprador dessas marcas.

Assim, nesse contexto, de que maneira o direito da criança e do adolescente pode ser resguardado pelo ordenamento jurídico brasileiro face ao protagonismo infantil diante da publicidade abusiva?

Dessa forma, faz-se necessário analisar o tema da publicidade abusiva e como ocorre essa prática em relação às crianças e aos adolescentes nas relações de consumo - uma vez que esse mecanismo pode trazer sérios prejuízos para o desenvolvimento psicológico e social destes -, além de identificar como tais categorias também são vítimas do abandono das instituições estatais, uma vez que falham no seu dever de fiscalizar e proibir esse tipo de publicidade abusiva. 
A metodologia utilizada nesta pesquisa é a dedutiva, combinada ao método dogmáticojurídico, baseada em pesquisa bibliográfica, com o objetivo de compreender o real alcance da publicidade destinada à criança e ao adolescente como sujeitos hipervulneráveis na relação de consumo, bem como verificar esse assédio sutil, impondo padrões estético-comportamentais potencialmente danosos à sua incolumidade desde muito cedo.

\section{A HISTÓRIA SOCIAL DA CRIANÇA E DO ADOLESCENTE E O PRINCÍ- PIO DA DIGNIDADE HUMANA}

Nos primórdios da Idade Média, as fontes bibliográficas que narravam a história social da infância eram escassas. Dessa forma, não era dada a devida atenção para a criança e para o adolescente, uma vez que estes eram tratados como miniaturas de adulto.

Apenas a partir século XIX, os historiadores nacionais e internacionais começaram a perceber a importância da criança e do adolescente como sujeitos de direito. Contudo, devido a mudanças ocorridas no início do século XX, as novas fontes e procedimentos da observação em pesquisas históricas tornaram possível a inclusão de pesquisas científicas acerca da história da criança e do adolescente. Tão só em 1970, foi publicado o livro "História Social da Infância e da Família", do historiador Philippe Ariès, no qual a história da criança e do adolescente passou a ser vista por um novo aspecto, o que gerou grande visibilidade à criança e ao adolescente como sujeitos de direito.

Ariès (2002) afirma que, em virtude do entendimento que se tinha da criança e do adolescente, a exploração do trabalho infantil e os maus tratos eram facilitados, uma vez que não eram considerados seres em desenvolvimento. Apenas no fim da Idade Média, o sentimento de infância passou a ser construído socialmente, pois, até então, as crianças eram tratadas como "adultos em miniatura" e necessitavam de cuidados básicos até conseguirem executar tudo sozinhas. Ariès (2002, p. 18) assegurava que "a criança, por muito tempo, não era vista como um ser em desenvolvimento, com características e necessidades próprias, e sim, homens de tamanho reduzido". O historiador aduz que as palavras "criança", "adolescente" e "adultos", conhecidos como "idades da vida", surgiram apenas na Idade Moderna (ARIÈS, 2002).

A infância hoje é entendida como o período que inicia com o nascimento e perdura até os 11 (onze) anos de idade do indivíduo. É o período no qual se inicia a vida humana. Na Idade Média, as pessoas tinham a ideia de que a infância era a primeira idade, considerada até o momento em que surgiam os dentes - o que ocorria do nascimento até os 7 (sete) anos de idade, período denominado enfant, que significa "ausência de fala", pois, nessa idade, a pessoa ainda não tem formada toda a sua capacidade de expressão. A segunda idade era considerada entre os 8 (oito) e os 14 (quatorze) anos de idade. Passado esse momento, o indivíduo já era considerado um adulto - o que hoje se entende como adolescente.

No Brasil, de acordo com Del Priore (2018), no século XVIII, época em que a escravidão ainda era permitida, as crianças escravas, quando completavam 12 (doze) anos de idade, já podiam se casar. Com 15 (quinze) anos, esses indivíduos (homens e mulheres) já eram considerados adultos e, entre os 24 (vinte e quatro) e os 35 (trinta e cinco) anos, eram considerados idosos. Em pleno século XIX, no Brasil, a definição do termo "infância" não era tão clara como na Europa, pois sua distinção estava relacionada ao desenvolvimento da capacidade física e mental do indivíduo. O termo "criança" apareceu no ano de 1830, ao passo que a expressão "adolescente" já existia, mas seu uso não era tão comum. 
A atenção com a criança é algo recente. No Brasil, apenas em 1927 tornou-se imprescindível o registro dos filhos. No mesmo ano, ocorreu a elaboração do Código de Menores, cuja visão era apenas punir adolescentes, pois, naquela época, a criança não tinha qualquer identificação e a sociedade não demostrava preocupação no cuidado com o desenvolvimento desta categoria. Paulatinamente, determinadas mudanças aconteceram, como a promulgação da Constituição Federal de 1988 e, mais emblematicamente, o Estatuto da Criança e do Adolescente (ECA), em 1990.

Em 1988, com a promulgação da chamada "Constituição Cidadã”, o Brasil passou a dar um novo tratamento para a criança, reconhecendo-a como sujeito de direitos e, consequentemente, estabelecendo um tratamento diferente de acordo com a sua formação e desenvolvimento.

A criança e o adolescente têm direito ao seu reconhecimento como sujeito de direito, pois quando a sociedade os trata sistematicamente como inferiores, internaliza-se uma imagem negativa e se passa a moldar as suas escolhas e ações a partir dessa imagem, influenciando, inclusive, o não desenvolvimento da autoestima destes indivíduos.

A palavra "reconhecimento" não denota a mera identificação do outro. O reconhecimento está associado à valorização da pessoa reconhecida, ou seja, trata-se de ato que lhe expressa o devido respeito. Assim, o ordenamento jurídico deve reconhecer a criança como sujeito de direito e obrigações, resguardando-lhe a dignidade da pessoa humana.

A negação de reconhecimento equivale ao desrespeito. Trata-se de um comportamento que não apenas insulta as pessoas ou lhes inflige dano, como também degrada a sua imagem. Nessa perspectiva, Sarmento (2016) desdobrou o reconhecimento em três esferas: amor, direito e solidariedade. Por outro lado, aludiu a três formas básicas de reconhecimento, que correspondem respectivamente à violação, à privação de direitos e à degradação.

Desta forma, é indubitavelmente necessário que o ordenamento jurídico ampare e dê total proteção à criança e ao adolescente, regulando os seus direitos e as suas garantias, superando a noção de que o adulto é superior a tudo, o que possibilitava que as transgressões contra a criança e ao adolescente não fossem penalizadas e apuradas, retirando assim o seu pleno desenvolvimento emocional e físico.

O direito à infância passou a ter status de direito fundamental, proibindo veementemente abusos. A doutrina da proteção integral deve se estender a todas as crianças e adolescentes, para dar reconhecimento dos direitos fundamentais inerentes à pessoa humana e, ainda, dos direitos especiais decorrentes da condição do sujeito de direito em desenvolvimento, consolidada pelo Estatuto da Criança e do Adolescente (ECA), em 1990.

\section{A legislação de CONSUMo, a Constituição da RePública DO BRASIL E A PROTEÇÃO DA CRIANÇA E DO ADOLESCENTE}

No presente capítulo, serão analisados a legislação de consumo e sua evolução, o contexto histórico e os dispositivos da Constituição Federal de 1988, bem como o protagonismo e a hipervulnerabilidade da criança e adolescente na relação de consumo. 


\subsection{A legislação de consumo e a Constituição da República do Brasil de 1988}

A legislação de consumo no Brasil efetivou-se após a promulgação da Constituição da República de 1988. A CF/88 consagrou os princípios gerais da ordem econômica, dentre os quais se destaca a defesa do consumidor, a qual se consolidou com a promulgação do Código de Defesa do Consumidor (CDC).

A atual Constituição da República brasileira estabeleceu princípios e fundamentos sociais de ordem econômica, uma vez que acompanhou a tendência de outras constituições sociais como a da Alemanha, de 1919, a da Rússia, de 1918 e a do México, de 1917.

O Estado, nos últimos anos, tem assumido o papel de protagonista econômico, realizando intervenções na economia com a máquina pública, em meio à doutrina social liberal, voltandose a regular o mercado pelo direito do consumidor, estabelecendo as diretrizes públicas no direito privado e na relação do consumo.

O sistema capitalista não aceita a intervenção do Estado no direito privado em uma perspectiva positiva. No entanto, constatou-se que o capitalismo descontrolado e regulado pelo próprio mercado, sem nenhuma regulamentação específica, acarretaria sérios prejuízos para o próprio capitalismo. Com a maturação desse sistema, percebeu-se a necessidade de resguardar e garantir os direitos fundamentais, por meio da intervenção do Estado, abrigando o direito do consumidor.

Nos Estados Unidos e na Europa, após os desequilíbrios econômicos e sociais ocorridos nas transformações experimentadas pós-revolução industrial, sentiu-se necessidade de movimentos consumeristas, que deram origem a instituições como Consumer's League. Mais tarde, esta se transformou em Consumer's Union, considerada uma das mais importantes instituições responsáveis pela avaliação dos produtos que são introduzidos no mercado do consumidor.

No Brasil, mesmo antes da Constituição Federal de 1988 e do Código de Defesa do Consumidor, o sistema jurídico já possuía normas que resguardavam alguns direitos do consumidor, como a lei que tratava de reprimir o crime de usura, normas que tratavam da economia popular, a lei de repressão ao abuso econômico, a lei de ação civil pública e a lei que tratou do crime contra o sistema financeiro.

A Constituição Federal de 1988 inovou ao reconhecer a proteção do consumidor no capítulo dos direitos e garantias fundamentais (artigo $5^{\circ}, \mathrm{XXXII}$ ), assim como no capítulo da ordem econômica (artigo 170, V). Com o objetivo de atender ao artigo 48 do Ato das Disposições Constitucionais Transitórias, foi elaborado o Código de Defesa do Consumidor, através da Lei 8.078/90, normatizando a publicidade e a relação de consumo no plano infraconstitucional.

Da mesma forma, a Constituição de 1988 inovou ao regularizar, nos dispositivos dos direitos fundamentais, um cuidado especial à criança e ao adolescente ao tratar da família, protegendo, inclusive, essa instituição do malefício de uma comunicação com viés abusivo, pois ficou entendido que a criança e o adolescente devem ser resguardados de qualquer forma de exploração, considerando sua hipervulnerabilidade.

A oferta e a publicidade dirigidas ao consumo devem ser veiculadas em estrita observância aos parâmetros legais, sobretudo quando direcionadas a uma categoria em desenvolvimento, como é o caso da criança e do adolescente. O Código de Defesa do Consumidor normatizou e proibiu a publicidade abusiva entendida como aquela que se aproveita da deficiência de julgamento da criança e do adolescente, além de outras especificações expostas no referido Código. 


\subsection{O protagonismo da criança e do adolescente}

O protagonismo infantil é uma expressão relativamente atual, utilizada para demostrar, em um processo social, o interesse superior da infância. Aurélio (2002) aduz que a palavra "protagonista" tem origem etimológica do grego protagonistés, que significa "ator principal" de uma peça teatral, filme, série, ou aquele que se destaca em qualquer acontecimento, área ou situação.

O papel desempenhado pela criança e pelo adolescente como protagonista é de destaque na comunidade e na sociedade, para que seus direitos fundamentais sejam resguardados acima de qualquer interesse que não lhes possibilite proteção e que prejudique seu pleno desenvolvimento físico e mental; de modo que a criança, como protagonista de seus direitos, possa demostrar aos adultos as suas reais necessidades e seus pontos de vista a respeito dos seus direitos fundamentais.

Na Convenção sobre os Direitos da Criança, definida pela Organização das Nações Unidas (ONU) em 1989, o Brasil foi um dos países signatários do tratado que resultou dos trabalhos desenvolvidos nesta. Dentro dos direitos elencados no referido tratado, os Estados-Parte são obrigados a garantir ao máximo a sobrevivência e o desenvolvimento da criança, assim como a proteção e os cuidados necessários ao bem-estar dela. A Convenção também assegura que a criança hábil a estabelecer seus próprios juízos precisa exercer "o direito de expressar suas opiniões livremente, sobre todos os assuntos relacionados à sua realidade, levando-se devidamente em consideração essas opiniões, em função da idade e maturidade da criança" (UNICEF, 1989).

Desse modo, a Convenção ainda garante o direito da criança à liberdade de expressão, que abarca "liberdade de procurar, receber e divulgar informações e ideias de todo tipo, independentemente de fronteiras, de forma oral, escrita ou impressa, por meio das artes ou por qualquer outro meio escolhido pela criança". Além disso, é direito da criança a liberdade de pensamento, de consciência e de crença.

Rizzini (2004) define que o ECA e a Constituição Federal de 1988 permitiram ao Brasil ser conhecido internacionalmente como um dos precursores da participação infantil em assuntos sobre as crianças.

Nesse sentido, o protagonismo infantil pode ser observado por meio de três perspectivas: 1- "organização infantil", 2- "participação infantil", 3- "expressão infantil”. As três têm como finalidades, entre outras: o impacto social para comover a família, outros setores relacionados às crianças e à Convenção da ONU, a presença da sociedade civil em um plano social a favor da infância, a convenção dos chefes de governos em reforçar as políticas públicas correspondentes com o projeto. As três perspectivas necessitam ser trabalhadas juntas para alcançar o mais perfeito efeito do protagonismo. Caso ocorra a separação delas, existe uma probabilidade enorme de desintegração do processo, eis que sua relação com os outros setores da sociedade provavelmente não será o mesmo.

A “organização infantil” é a mobilização de crianças e adolescentes com a finalidade de concretizar os seus direitos fundamentais, sendo capaz de acontecer em diferentes planos: seja local, municipal, estatal ou em contextos comunitário e/ou escolar. Com efeito, mesmo que tenham o papel de protagonista, crianças e adolescentes podem contar com a ajuda de adultos.

A "participação infantil" é o procedimento que tem o objetivo de aumentar o poder de crianças e adolescentes em sua participação na relação com os adultos. A atuação resguarda a legitimidade e incidência social do protagonismo infantil, enquanto a "expressão infantil" é a capacidade que a criança e o adolescente têm de ser, pensar e se sentir como sujeito em uma 
sociedade, ou seja: as crianças e os adolescentes têm a possibilidade de desenvolver estruturas propícias para expressar seus sentimentos e pensamentos.

O protagonismo infantil tem muitos pontos positivos, tais como a aproximação da convivência entre os filhos e os pais, com maior participação da criança e maior acatamento às opiniões dela. No entanto, nem todos os resultados são equilibrados, pois, passados alguns anos, o mercado tem utilizado o papel de protagonismo da criança para manipular adultos no sentido de adquirirem produtos que são disponibilizados pela publicidade direcionada para o público infantil.

A teoria sobre o desaparecimento da infância, desenvolvida por Postman (1999), é associada ao protagonismo infantil, onde a criança, aos poucos, tem sido "adultizada", ou seja, a criança está sendo associada cada vez mais ao adulto. Uma das razões para o autor da teoria atribuir esse comportamento seria a televisão, uma vez que ela apresenta, na publicidade e nas grades de informações, os valores e os estilos dominantes: "e em nossa situação atual os valores e estilos da criança e os dos adultos tendem a se fundir" (POSTMAN, 1999, p. 142).

\subsection{A hipervulnerabilidade da criança e do adolescente e o Código de Defesa do Consumidor}

A palavra vulnerável é derivada do latim, do verbo vulnerare, e significa "provocar um dano". Ademais, o adjetivo "vulnerável" deriva de vulnus, também do latim, que significa machucado, atacado por um mal ou frágil (MARQUES, 2012, p. 202). A referida palavra demonstra a sua acepção de fraqueza ou risco de um grupo e é utilizada por distintos campos da ciência que trabalham com a vida humana, tais como o Direito e a Medicina. Destarte, os seres humanos são vulneráveis em algum aspecto, potencialmente expostos a um enorme número de riscos e condições de exclusão social.

O Código de Defesa do Consumidor sopesa que o consumidor é a parte vulnerável na relação de consumo. O princípio da vulnerabilidade é um princípio estruturante e informador da Política Nacional de Relações de Consumo.

Desse modo, a vulnerabilidade tem um conceito jurídico rotulado como de direito material, que demonstra a ocorrência de desequilíbrio praticada pelo agente econômico e o consumidor, diante do fornecedor de produtos ou serviços. A fragilidade é afrontada pelas próprias qualidades essenciais do público infantil.

O inciso I do art. $4^{\circ}$, do Código de Defesa do Consumidor, reconhece que o consumidor é notadamente vulnerável no mercado de consumo, pela sua própria qualidade essencial de ser a parte mais fraca na relação de consumo. No entanto, há espécies de consumidores que apresentam condições específicas, como é o caso das crianças, dos idosos e das pessoas com deficiência, passando a ser denominados consumidores hipervulneráveis ou portadores de uma vulnerabilidade existencial ou agravada.

A vulnerabilidade existencial da criança e do adolescente encontra-se associada à sua personalidade ainda em desenvolvimento. A Constituição Federal de 1988, em seu art. 227, §3º, consagra o princípio da proteção integral à criança e ao adolescente, assim dispondo:

A criança e adolescente gozam de todos os direitos fundamentais inerentes à pessoa humana, sem prejuízo da proteção integral de que trata esta Lei, assegurando-lhes, 


\begin{abstract}
por lei ou por outros meios, todas as oportunidades e facilidades, a fim de lhes facultar o desenvolvimento físico, mental, moral, espiritual e social, em condições de liberdade e de dignidade.
\end{abstract}

A criança e o adolescente, a partir de seu nascimento, demandam amparo material e afetivo, pois encontram-se em construção a sua personalidade e as suas estruturas física e mental. Assim, Konder (2015, p. 06) cita Iencarelli:

O ser humano nasce muito frágil e com várias necessidades de cuidado, que comprometem sua sobrevivência. É indispensável que alguém lhe forneça e zele pelo alimento, pela higiene do corpo, pelo sono, e pelo colo. O cuidado, portanto, se constitui no condutor que o levará deste estado de vulnerabilidade absoluta ao processo de aquisição de autonomia, e, consequentemente, de humanização.

Sendo assim, a vulnerabilidade existencial ou hipervulnerabilidade deve prescindir de qualquer tipificação. Ela é decorrente da aplicação dos princípios constitucionais da dignidade da pessoa humana e da solidariedade social.

A respeito da vulnerabilidade existencial ou hipervulnerabilidade da criança frente à publicidade, destaca Schimitt:

\begin{abstract}
Assevera-se que as crianças não têm condições de compreensão e entendimento do conteúdo implícito presente na informação publicitária, muito menos, seu caráter persuasivo, incentivador do consumo. Aliás, esses indivíduos sequer têm o entendimento necessário para observar que dada comunicação é publicidade. Evidentemente, um adulto possui muito mais força de resistência mental e de apreensão da realidade do que uma criança, podendo enfrentar a pressão exercida pela publicidade. A ausência dessa característica na criança, que não tem aptidão para analisar criticamente uma dada informação, deflagra um grau maior de vulnerabilidade, de forma que ela se enquadra também na concepção de hipervulnerabilidade. (SCHIMITT, 2014, p. 229).
\end{abstract}

Destarte, as crianças exercem poder nas decisões de consumo em relação às compras realizadas pelos pais, frente à hipervulnerabilidade que apresentam diante da relação com os fornecedores de produtos ou serviços. A criança está em um período de vida em que o seu estado psicológico de desenvolvimento permite que seja convencida com maior facilidade, uma vez que sua formação intelectual não está completa para analisar a relação contratual com maior profundidade, tampouco os aspectos financeiros envolvidos na relação de consumo. Assim, faz-se necessário que sejam analisados os aspectos da publicidade e o protagonismo da criança e do adolescente na relação de consumo, o que será feito no próximo capítulo.

\title{
3. A PUBLICIDADE ABUSIVA E O PROTAGONISMO NA RELAÇÃO DE CONSUMO DA CRIANÇA E ADOLESCENTE
}

As crianças na atualidade têm uma importante função nas tomadas de decisões dos adultos quanto ao consumo de produtos e serviços que são destinados para o consumo das famílias. Os profissionais da área de publicidade, de olho no consumo e no poder que as crianças exercem sobre os pais, utilizam-se dos infantes como instrumentos de convencimento da publicidade abusiva, para aumentar as vendas de produtos e serviços. É sobre os aspectos de publicidade abusiva e o protagonismo da criança e do adolescente na relação de consumo que se pretende discorrer neste capítulo. 


\subsection{A publicidade abusiva}

É importante ressaltar que alguns doutrinadores diferem entre publicidade e propaganda, uma vez que a segunda é definida por Denari, citado por Ramos e Zanatta (2015, p. 189), como: "a divulgação de qualquer ideia com o fito de fazer proselitismo político, social ou religioso".

Destaca Miragem (2014, p. 3-4) que "a atividade publicitária é inerente ao mercado de consumo contemporâneo. Seus efeitos, aliás, ultrapassam uma perspectiva meramente econômica, influenciando na definição de comportamentos sociais".

O Código de Defesa do Consumidor procura apresentar diretrizes a respeito da publicidade, estabelecendo a proibição de qualquer forma de publicidade ilícita. Dessa forma, o conceito de ilicitude da publicidade transcorre de dois tipos: 1- Publicidade enganosa e 2- publicidade abusiva.

No presente artigo, será discutida apenas a publicidade abusiva. É de se ressaltar que a publicidade ilícita provoca afronta ao princípio da segurança, de maneira a dissimular o produto. Diante da "ignorância" do consumidor, absorve sua fé e o induz a adquirir o produto. Ressaltese que a publicidade abusiva é indutora de insegurança, uma vez que o consumidor é levado a consumir um produto de forma prejudicial ou perigosa à sua saúde ou segurança.

O Código de Defesa do Consumidor procurou apresentar em seu dispositivo um rol apenas exemplificativo do que seja publicidade abusiva. Desta forma, o aplicador da lei deve, no caso concreto, fazer uma interpretação dos dispositivos elencados no Código, com o propósito de resguardar da melhor forma o consumidor - que é a parte mais vulnerável da relação de consumo.

A respeito da publicidade abusiva, o artigo 37 do Código de Defesa do Consumidor dispõe que:
Art. 37. É proibida toda publicidade enganosa ou abusiva.
$\S 2^{\circ}$ - É abusiva, dentre outras a publicidade discriminatória de qualquer natureza, a que incite à violência, explore o medo ou a superstição, se aproveite da deficiência de julgamento e experiência da criança, desrespeita valores ambientais, ou que seja capaz de induzir o consumidor a se comportar de forma prejudicial ou perigosa à sua saúde ou segurança.

É de se observar, ainda, que a proibição à publicidade abusiva tem a finalidade de romper a divulgação de mensagens que afrontem valores sociais, éticos e morais e também a ordem pública. De todo modo, a publicidade abusiva pode ser subdividida em: 1- "discriminatória", 2"exploradora do medo ou superstição", 3- "incitadora de violência", 4- "dirigida à criança", 5"antiambiental" e 6- "indutora de insegurança".

A publicidade abusiva discriminatória, de acordo com Tessaro (2014), é aquela que segrega o ser humano em razão de sua etnia, origem, sexo, religião etc. Ademais, ofende o princípio da igualdade, previsto expressamente na Constituição Federal de 1988.

Quanto à exploradora do medo ou superstição, é aquela cuja utilização é para convencer o consumidor a comprar determinado produto. Não é imperioso que se cause temor para ser designada como tal, mas apenas que se utilize desses artifícios para ser considerada ilegítima.

Marques, Bessa e Benjamin (2014) apontam que as mensagens publicitárias que incitam violência são aquelas que se utilizam de anúncios relativos a agressões, morte ou guerra. Em decorrência disso, não são toleradas pelo ordenamento jurídico brasileiro. 
A publicidade destinada à criança, dependendo de seu conteúdo e modo de veiculação, pode vir a ser considerada abusiva justamente por sua maior fragilidade em entender seu real alcance. As empresas utilizam a publicidade como principal instrumento para divulgar seus produtos e serviços, sobrevalorizando suas qualidades e características e criando artificialmente novos desejos.

No âmbito das novas plataformas digitais, como redes sociais, blogs e provedores de conteúdo, o controle publicitário é ainda mais difícil, sobretudo pelo dinamismo e caráter subliminar das mensagens, comumente veiculadas pelos conselheiros digitais com grande apelo popular, sem a observância do princípio da identificação publicitária, previsto no artigo 36 do CDC.

Percebe-se que boa parte das mensagens publicitárias é destinada ao público infantil, o qual é hipervulnerável, como já demostrado neste artigo, de modo que se passa à análise do protagonismo da criança e do adolescente e a publicidade na relação de consumo.

\title{
3.2. O protagonismo da criança e adolescente e publicidade infantil na relação de consumo
}

A criança é um ser que se encontra em desenvolvimento físico, psicológico e social. Desse modo, não se acha capaz para entender o caráter persuasivo e, na maior parte das vezes, sublinear dos anúncios publicitários, uma vez que os anúncios destinados para o público infantil se valem da deficiência de julgamento e de experiência deste.

Para Fernandes (2010, p. 45), “a publicidade dirigida à criança deve ter limites restritos porque a criança, diferentemente do adulto, não possui discernimento para compreendê-la em sua magnitude".

Verbicaro e Silva (2017, p. 04) afirmam que:

\begin{abstract}
A abordagem utilizada é agressiva, fruto de um verdadeiro assédio, subjugando a capacidade de escolha e reflexão do indivíduo, obrigando-o a decidir por impulso e de acordo com um único padrão estético estabelecido, o que naturalmente se agrava se o destinatário da mensagem for uma criança, cujo desenvolvimento intelectual incompleto a impede de discernir, ou mesmo de se precaver de conteúdos invasivos e não menos abusivos, daí porque é possível falar de que o público infantil se enquadra na categoria dos "hipervulneráveis".
\end{abstract}

A mídia tem percebido a influência da criança e do adolescente e, na tentativa de aproveitar-se da ingenuidade deles para vender seus produtos, utiliza a publicidade abusiva, uma vez que os adultos sofrem forte influência no momento de aquisição de produtos e serviços.

As pesquisas evidenciam o protagonismo infantil em relação às decisões de compra de uma família:

Conforme pesquisa da TNS/ Interscience realizada em outubro de 2003, o poder de
influência das crianças na hora das compras chega, hoje, a $80 \%$ (oitenta por cento)
em relação a tudo que é comprado pela família, desde o automóvel do pai, à cor do
vestido da mãe, passando, inclusive, pelo próprio imóvel do casal. Quando o assunto
é escolha alimentos, esse número é $78 \%$ (setenta e oito por cento) do que é consumido
pela família. (MOREIRA, RAUEN, ROSSI apud TESSARO, 2014, p. 152).

É evidente a capacidade que a publicidade exerce sobre os seres humanos, retirando o obstáculo entre a realidade e a "irrealidade". É perceptível, assim, que as crianças estão sendo seduzidas pela mídia, que costuma determinar convergências nem sempre saudáveis, apenas com 
o desígnio de alcançar ganhos e menosprezando direitos fundamentais para um desenvolvimento saudável e livre de abusos consumeristas.

Diante dessa nova perspectiva publicitária, é inimaginável não perceber nos anúncios, em especial nos comerciais de televisão, uma alteração de grande significado com relação à abordagem, em que os convites são confeccionados para alcançar mais as crianças do que os pais. Porém, para se alcançar efeitos positivos, os publicitários estão aperfeiçoando as técnicas de como ingressar no universo infantil, estudando o mundo da criança e procurando identificar o que realmente gostam.

Percebe-se, assim, que os pais, quando estão acompanhados pelas crianças em determinadas ocasiões, são pressionados a encherem seus carrinhos de compras com produtos que as crianças anseiam - que, por vezes, não são de maiores utilidades, servindo apenas para satisfazer um desejo que foi imposto pela publicidade à criança.

Desta forma, observa-se que as crianças têm papel decisivo nas compras da família, impondo seus desejos relacionados aos produtos adquiridos pelos pais, pois os influenciam a adquirirem os produtos destinados ao consumo conjunto durante as férias familiares ou dos carros, bem como produtos usados apenas por seus pais.

Nesse sentido, Sampaio (2008, p. 66) cita Ribes, doutora em educação, em entrevista concedida a "Encontros com a Mídia": "Dizer que a criança é ou não é consumidora, tendo como base a posse do dinheiro, é uma questão complexa que tem relação com a forma como as crianças habitam/vivenciam a família e a escola.".

A criança, apesar de não ter renda própria, é atacada pela grande multidão de produtos e serviços disseminados com grande constância no mercado. Os produtos oferecidos nos mercados, as embalagens, os brindes e as guloseimas produzem grande euforia no público infantil, influenciando as crianças a constrangerem seus pais a contrair produtos fora da lista de compras cotidianas e, muitas vezes, supérfluos para muitas famílias.

Importante observar a afirmação do sociólogo e jornalista Clóvis Barros Filho (2008), na $4^{\text {a }}$ Conferência Anual de Publicidade e de Promoção para Crianças - evento voltado para premiar os melhores publicitários que trabalham com publicidade no mercado infantil, realizado em setembro de 2001. Um dos participantes do evento observou o aumento da influência das crianças no consumo, dizendo que o mercado infantil é atualmente o setor mais poderoso do mercado.

Entretanto, não houve qualquer observação a respeito da publicidade abusiva em relação à criança e ao adolescente, à ética ou à responsabilidade social, preocupando-se apenas com o protagonismo infantil e o lucro que a publicidade pode gerar explorando o público infantil e o mercado decorrente deste público.

Destarte, a publicidade abusiva destinada às crianças, sendo estas protagonistas da relação de consumo, trata-se de uma violência sutil, implementando costumes e determinando valores na vida da criança desde muito cedo, possibilitando, desse modo, alterar uma vida - uma vez que esse tipo de publicidade instrui que somente por meio do consumo se pode alcançar o modelo capitalista de felicidade.

O projeto "Criança e Consumo", do Instituto Alana, criou uma campanha "\#AnunciaPraMim”, com o objetivo de influenciar e incentivar os pais a fazerem denúncias contra empresas que praticam a publicidade infantil abusiva, propondo-as para que essas informações não sejam direcionadas especificamente para crianças e sim que atinjam o público adulto, uma vez que ele possui capacidade econômica para decidir o que crianças e adolescentes vão consumir, tendo 
também maior percepção para distinguir o que será prejudicial ao pleno desenvolvimento da infância e da adolescência.

Desse modo, é preciso combater o assédio do mercado em relação à criança, então denominada "consumidor do futuro", induzindo-a em seus primeiros anos de vida a desenvolver hábitos de consumo nocivos e prejudiciais ao seu desenvolvimento, bem como a instigar adultos a adquirirem produtos, através de seu poder de persuasão e protagonismo.

\section{CONSIDERAÇÕES FINAIS}

O texto abordou a publicidade abusiva e o protagonismo da criança e do adolescente na relação de consumo, apresentando o contexto em que os historiadores nacionais e internacionais começaram a dar real importância à criança e ao adolescente, reconhecendo-os como sujeitos de direito, assim como sua hipervulnerabilidade na relação de consumo.

Dessa forma, é indiscutível que o ordenamento jurídico deve assegurar total proteção à criança e ao adolescente, regulando os seus direitos e suas garantias, superando a noção de que o adulto é superior a tudo, pois, quando se agia desta forma anteriormente, dava-se azo para que as transgressões contra a criança e o adolescente não fossem penalizadas e apuradas, retirando assim o seu pleno desenvolvimento físico e emocional.

A criança e o adolescente têm direito ao seu reconhecimento como sujeitos de direito, pois quando a sociedade os trata sistematicamente como inferiores, reproduz-se uma imagem negativa deles mesmos, tendendo a não desenvolver a autoconfiança.

O infante é um ser humano em desenvolvimento, possuidor de vulnerabilidade existencial ou hipervulnerabilidade, pois não possui a capacidade de discernimento plenamente desenvolvida, quando exposto e submetido à publicidade abusiva, de forma a acarretar sérios prejuízos de ordem psicológica e econômica, causando danos ao seu desenvolvimento saudável e comportamento social.

Destarte, não é suficiente apenas denunciar e censurar o mercado da publicidade abusiva e o protagonismo da infância. Além disso, é preciso que se articulem mecanismos públicos de controle e movimentos sociais para possibilitar que a criança e o adolescente se desenvolvam em rudimentos saudáveis, de forma que a sua identidade, seus valores e seu pensamento de futuro não sejam corrompidos pela publicidade abusiva.

Nesse contexto, medidas como a campanha "\#AnunciaPraMim”, do Instituto Alana, são necessárias, pois servem de alerta para os pais e incentivam denúncias contra empresas que se valem da publicidade infantil abusiva para angariarem lucro.

É preciso, ainda, que as normas que regulamentam a publicidade sejam respeitadas e que o próprio fornecedor de produtos e serviços se autofiscalize, utilizando um monitoramento preventivo contra a publicidade ilícita e adotando normas para que a criança e o adolescente não sejam usados como instrumento de publicidade abusiva. A busca de uma aproximação ética com seu público consumidor, justamente pelo respeito aos direitos da criança e do adolescente, forja um novo modelo de atuação empresarial, voltado para o fortalecimento de uma identidade com a marca (branding), fidelizando, em última análise, o consumidor.

É importante que haja um crescimento saudável dos infantes, pois estes são seres que se encontram em desenvolvimento. Ainda, é imprescindível que haja um fortalecimento das relações familiares, bem como que os órgãos responsáveis pela fiscalização e proteção da criança e adolescente desempenhem o seu papel de combate à publicidade abusiva. 
Assim, a publicidade direcionada à criança e ao adolescente exige um controle normativo mais rigoroso, posto que a sua capacidade de decisão é limitada, em razão de seu desenvolvimento físico e emocional incompletos. Nesse sentido, é possível reconhecê-los como portadores de uma vulnerabilidade agravada, na medida em que estão mais suscetíveis a padrões estéticoscomportamentais nocivos - como, por exemplo, nos casos de obesidade infantil, sexualidade precoce, bullying ou mesmo num inadvertido apelo para a superação prematura de suas infâncias.

O maior empoderamento dos consumidores no mercado, quando passam a exercer sua liberdade de escolha de forma mais qualificada, permite a eles selecionar fornecedores que não apenas respeitem o adequado desenvolvimento da criança e do adolescente pela veiculação de publicidade responsável, mas também lhes possibilita influir na mudança do comportamento ético do empresário, seja pela postagem de experiências negativas nas redes sociais e sites de compartilhamento de experiências, seja pelo boicote de produtos e serviços nocivos ao público infantil.

\section{REFERÊNCIAS}

ARIÈS, Philippe. História social da família da criança e da família. 2.ed. SãoPaulo: LCT, 2018.

AURELIO. O minidicionário da língua portuguesa. 4 ed. rev. e amp. do mini dicionário Aurélio. Rio de Janeiro, 2002.

BAUMAN, Zygmunt. Vida para consumo: a transformação das pessoas em mercadoria. Rio de Janeiro: Zahar, 2008.

BENJAMIN, Walter. Reflexões sobre a criança, o brinquedo e a educação. São Paulo: Editora 34, 2002.

BRASIL. Constituição Federativa de 1988. Disponível em: http://www.planalto.gov.br/ccivil 03/constituição/constituição,html. Acesso em: 14 jan 2019.

BRASIL. Lei 8.069/90. Estatuto da Criança e do Adolescente. 2009. Disponível em: http://www. planalto.gov.br/ccivil_03/leis/18069,html. Acesso em: 14 jan 2019.

COOK, Daniel Thomas. The Commodification of chilldhood: the children's clothing industry and the rise the chid consumer. Durham \& London: Duke University Press, 2004.

COSTA, Marconi Freitas; LIMA, Raniere de Franca; SANTOS, Paula Janaine; VIEIRA, Maria das Graças. Comportamento do consumidor infantil: um estudo do consumo dos pais em supermercados através da influência dos filhos no momento da compra. Disponível em: http://docplayer.com.br/12484635-Comportamento-do-consumidor-infantil-um-estudo-do-consumodos-pais-em-supermercados-atraves-da influencia-dos-filhos-no-momento-da-compra.html. Acesso em: 05 jan. 2019.

DEL PRIORE, Marry. História das Crianças no Brasil. Ed. São Paulo: Contexto, 2018.

DIAS, Lucia Ancona Lopez de Magalhães. Publicidade e hipervulneráveis: limitar, proibir ou regular? Revista de Direito do Consumidor. vol 99, ano 24, p. 285-305. São Paulo: Ed. RT, maio-jun, 2015.

FERNANDES, Marília Milioli. A publicidade abusiva diante da hipossuficiência da criança: Um estudo à luz do princípio da proteção integral. Disponível em: http://repositorio.unesc.net/ 
bitstream/handle/1/369/Mar\%C3\%ADlia\%20Milioli\%20Fernandes.PDF?sequence=1. Acesso em: 14 jan 2019.

HENRIQUES, Isabella. Publicidade abusiva dirigida à criança. Curitiba: Juruá Editora, 2006.

JACOBINA, Paulo Vasconcelos. A Publicidade no Direito do Consumidor. Rio de Janeiro: Forense, 2002.

KONDER, Carlos Nelson. Vulnerabilidade patrimonial e vulnerabilidade existencial: por um sistema diferenciador. Revista de Direito do Consumidor, vol. 99/2015, p. 101 - 123, maiojun. 2015.

KRAMPE, Francieli Daiane. A Publicidade das Bebidas Alcoólicas e os Parâmetros do Direito. Cascavel, 2013.

LINN, Susan. Crianças do consumo: a infância roubada. São Paulo: Instituto Alana, 2006.

MARQUES, Cláudia Lima. Diálogo das Fontes: do conflito à coordenação de normas do direito brasileiro. 1. ed. São Paulo: Editora Revista dos Tribunais, 2012.

MARQUES, Claudia Lima; BESSA, Leonardo Rosco; BANJAMIN, Antonio Herman de Vasconcellos. Manual de Direito do Consumidor. 6 ed. RJ: Rio de Janeiro, Revista dos Tribunais, 2014.

MILC - Movimento infância livre de consumismo. Disponível em: http://milc.net.br/2014/ 08/os-limites-legais-da-publicidade-infantil-no-direito-brasileiro/\#.VQXWjtLF_1Y. Acesso em: 11 jan. 2019.

MIRAGEM. Bruno. A Constitucionalidade da Resolução 163 do Conselho Nacional dos Direitos da Criança e do Adolescente (CONANDA). Disponível em: http://criancaeconsumo. org.br/wpcontent/uploads/2014/02/Parecer_ProfBrunoMiragem.pdf. Acesso em: 10 jan. 2019.

NUNES, Rizzatto. Curso de direito do consumidor. São Paulo: Saraiva, 2015.

POSTMAN, Neil. O Desaparecimento da Infância. Tradução: Suzana Menescal de A. Carvalho e José Laurenio de Melo. RJ: Grafhia Editorial, 1999.

PROJETO CRIANÇA E CONSUMO. Por que a publicidade faz mal para as crianças. Instituto Alana, 2009. Disponível em: http://criancaeconsumo.org.br/wp-content/uploads/2014/02/ por-que-a-publicidade-faz-mal-para-as-criancas.pdf. Acesso em: 05 jan. 2019.

RAMOS, Fabiane D'Andrea; ZANATTA, Lisiane. Fundamentos principiológicos para a proibição de publicidade dirigida à criança no Brasil. Revista da Faculdade de Direito da UFRGS, 2017. Disponível em: https://seer.ufrgs.br/revfacdir/article/download/68431/46263. Acesso em: 10 jan. 2019.

RIZZINI, Irene. Infância e globalização: análise das transformações econômicas, políticas e sociais. Revista de Sociologia da Universidade de Lisboa, Problemas e Práticas. Portugal, v. 44, p. 11-26, 2004.

SAMPAIO, Fernanda Tiosso. As abusividades da publicidade e o público infantil. Disponível em: http://intertemas.unitoledo.br/revista/index.php/Juridica/article/viewFile/681/752. Acesso em: 12 jan. 2019.

SANDRI, Jean Carlos; SILVA, Alexandre Barbosa da. O controle da publicidade abusiva destinada a crianças. Revista de Estudos Jurídicos e Sociais. Cascavel, 3. ed., n. 3, p. 189-217, ago. 2014. 
SARMENTO, Daniel. Dignidade da pessoa humana, conteúdo, trajetória e metodologia. Belo Horizonte: Ed. Fórum, 2016.

SCHMITT, Cristiano Heineck..Consumidores hipervulneráveis: a proteção do idoso no mercado de consumo. 1. ed. São Paulo: Editora Atlas, 2014.

SOUZA, Maristela Denise Marques de. Responsabilidade socioambiental da publicidade a partir da análise jurídica da publicidade ilícita que não atende os valores socioambientais. Curitiba: 2014. Tese (Doutorado em Direito) - Pontifícia Universidade Católica do Paraná.

TESSARO, Eduardo Felipe. A publicidade infantil e a obesidade: O papel do direito na proteção do cidadão. Berlin: Novas Edições Acadêmicas, 2014.

VALOIS, Bertha Lilia e Silva. Publicidade dirigida à criança: A necessidade de uma regulamentação específica. Universidade Católica de Pernambuco. Disponível em: http://www.unicap. br/tede/tde_arquivos/4/TDE-2013-08-21T162107Z 586/Publico/bertha_lilia_silva_valois.pdf. Acesso em: 14 jan. 2019.

VERBICARO; Dennis; SILVA, Camille Barroso. O assédio de consumo no âmbito da publicidade infantil. Revista Direitos sociais e políticas públicas (Unifafibe). Disponível em: www. unifafibe.com.br/revista/index.php/direitos-sociais-politicas-pub/article/.../pdf_1. Acesso em: 10 jan. 2019.

Submetido em: 27 maio 2019.

Aceito em: 23 ago. 2020. 